\title{
El holismo cosmoteándrico de Raimon Panikkar y el holismo sustancial de Fernando Inciarte: ¿dos metafísicas de sistema?
}

\author{
Zaida Espinosa \\ Universidad Loyola Andalucía
}

Resumen: Este artículo se dirige a contrastar las metafisicas de Raimon Panikkar y Fernando Inciarte. Al examinar, en las dos primeras partes, sus formas de contestar a la pregunta metafisica fundamental por lo que es, encontramos las respuestas aparentemente contrapuestas de una metafisica de la sustancia (Inciarte) y una metafisica del sistema basada en la intuición cosmoteándrica que tiene como categoria clave la relación (Panikkar). En la tercera parte se relacionan ambos planteamientos para indagar qué papel juega la noción de sistema en ellos y determinar finalmente que el pensamiento de la sustancia no está tan lejos del pensamiento de sistema como puede parecer.

Palabras clave: sustancia; relación; función; sistema; Panikkar

Abstract: "Ramon Panikkar's Cosmotheandric Holism and Fernando Inciarte's Substantial Holism: Two Metaphysics of System?". The aim of this article is to compare the metaphysics of Raimon Panikkar and Fernando Inciarte. When examining, in the first two parts, the way in which both answer to the main metaphysical question of what it is, we find the apparently opposed approaches of a metaphysics of substance (Inciarte) and a metaphysics of the system based on the cosmotheandric intuition, which has relations as the fundamental category (Panikkar). In the third part, we compare both approaches in order to assess the role that the notion of system plays in them so as to determine, in the end, that the metaphysics of substance is more related to the metaphysics of the system than it may appear at first.

Keywords: substance; relation; function; system; Panikkar 


\section{Introducción}

El propósito de este trabajo radica en revisar y contrastar las metafísicas de dos autores del siglo XX, Raimon Panikkar y Fernando Inciarte, quienes han sabido abordar teóricamente uno de los desafios más importantes del presente: la necesidad de superar los dualismos separadores desde un pensamiento de la relación, al detectar el tipo de planteamientos deficientes que llevan hacia ellos. Cada autor sitúa el problema en planos distintos: cultural y religioso, en el caso de Panikkar, desde el contexto social global del presente; y metafísico, en el de Inciarte. Pero, a través de caminos diversos -el diálogo intercultural de Panikkar y la reinterpretación de conceptos filosóficos tradicionales en Inciarte- se examinará cómo ambos enfrentan este mismo objetivo último como reto fundamental del tiempo presente.

La riqueza de sus planteamientos puede calcularse desde su extensión -puesto que sus pensamientos tienen una ambición integral, relacional, lo abarcan todo, sin constreñirse a la estrechez de un campo específico de conocimiento- e intensión -por su radicalidad y profundidad, ya que buscan dar respuesta a las cuestiones últimas en fidelidad a las aspiraciones de una ciencia primera-.

Aplicando esto a sus modos de hacer filosofia, esto significa que no se conforman con una ontología estricta como función del filósofo profesional que elabora su saber desde una facultad específica en el lenguaje especializado que solo entienden los que comparten su formación académica, como acusa Orrego $^{1}$ en la universidad de investigación que tenemos configurada, sino que recuperan el significado de una metafisica integral -teofísica, en la aportación específica de Panikkar- como unidad de todos los saberes, esto es, una filosofia primera que apela a todos y que aborda, desde el lenguaje de la distinción, las preguntas fundamentales o cuestiones de raíz que no prescinden de lo divino, 316 sino que necesariamente lo abordan.

La perspectiva macroscópica que adopta Panikkar -tanto en el espacio, a través de la consideración de diferentes tradiciones, como en el tiempo, en el análisis de la evolución de las diferentes fases de la conciencia humana- permite una auto interpretación del sujeto más ajustada, la cual señala la nueva dirección que ha de tomar el pensamiento para insuflarle nuevo vigor. Solo mediante el examen de aquello que nos ocurre desde esta vista ensanchada, que toma 
distancia de los propios presupuestos culturales y de las categorias de cada época, puede advertirse el sentido objetivo de lo que tiene lugar, de aquello que el individuo debe reconstruir subjetivamente desde modos particulares o locales.

Aproximándonos a la tercera década del siglo XXI, resulta patente cómo la separación de los saberes y la extrema especialización lleva al empobrecimiento tanto del ser humano como persona, quien es algo más que un sujeto cognoscente, como del mundo que este habita, que es algo más que pura materia inerte o recurso de explotación.

El trabajo se va a estructurar en tres partes. En las dos primeras se indaga en la forma de contestar de los dos autores a la pregunta metafísica fundamental por lo que es, de manera que se perfile una caracterización de sus respectivas metafísicas. En ellas nos encontramos con respuestas aparentemente contrapuestas de una metafísica de la sustancia, en el caso de Inciarte, y una metafísica del sistema basada en la intuición cosmoteándrica que tiene como categoría clave la relación, en el de Panikkar. En la tercera se establece una relación explícita entre ambos planteamientos. En concreto, se estudiará qué papel juega la noción de sistema en ellos para valorar si puede aplicarse de manera acertada a ambos. De este modo, el objetivo último será evaluar el grado de contraste entre ambas propuestas, sus discrepancias y puntos de unión (como la crítica al sustancialismo, o la necesidad de superar una perspectiva meramente lógica), para determinar si sus diferentes caminos se encuentran en un término o intención semejante.

\section{La metafísica de la relación o el holismo cosmoteándrico de Raimon Panikkar}

\subsection{La crítica a la filosofía tradicional. El pensamiento funcional}

Panikkar disiente respecto a las dos ideas básicas de Parménides, originarias de toda la metafisica:

(1) Que el ser es y el no ser no es. Para él, el "siendo", el in-sistir (en el espacio y en el tiempo) es tan fundamental como el ex-istir (fuera de la nada), por lo que reclama la necesidad de reparar en el proceso (espacio-temporal) frente a la sustancia en sentido metafísico, que es o no es, sin admitir término medio.

(2) Que el ser sea conocido por el pensar². A este último aspecto se refiere al hablar de la "libertad óntica", "la libertad de la naturaleza, es decir,

2 Cf. Panikkar, R., Paz e interculturalidad. Una reflexión filosófica, Barcelona: Herder, 2006.

3 Panikkar, R., The Intrareligious Dialogue, Nueva York: Paulist Press, 1999, 33. 
la superación del dogma de Parménides sobre la 'esclavitud' de la realidad con respecto al pensamiento" ${ }^{4}$. Esto es así porque defiende que no hay paralelismo entre el orden del ser y el del pensar, ya que el ser es inagotable e inaprehensible en su riqueza. En su infinita trascendencia e inmanencia, "no necesita tener o seguir leyes" , y por ello solo es abarcable con el espíritu, que es también libertad y está más allá de las reglas del logos. Lo mismo ocurre respecto a la vida humana: esta "no se reduce a su comprensión lógica". autor, además, su tesis característica del pluralismo de la verdad que exige la localización de equivalencias homeomórficas entre las diferentes tradiciones ${ }^{7}$. Esto, sin embargo, no conlleva una minusvaloración de la racionalidad: "El logos representa la gran dignidad del hombre, pero existe también el espíritu -que no está subordinado al anterior" ${ }^{8}$.

Panikkar alude a otras tradiciones para las que es absurdo hablar de un Dios que tenga que seguir leyes que lo constriñan: "El on es mayor que el logos" ${ }^{\prime \prime}$, en consecuencia, lo que puede aparecer al juicio racional como contradictorio puede ser superado cuando se emplea otra fuente de comprensión de lo real. Según el autor, las dificultades que encontramos para asumir este hecho tienen que ver con el que "el árbol del saber nos tienta una y otra vez al precio de olvidarnos del árbol más importante, el árbol de la vida”" ${ }^{10}$ En el mismo sentido, apunta su distinción entre sentido y significado conceptual: "Algo puede 'tener sentido' para nosotros y sin embargo podemos encontrarlo carente de significado" ". Dice también que "el Ser no se piensa (comprende, concibe, aprehende), sino que se es consciente de él; no se 've', pero se 'escucha"12.

Así pues, (1) tiene que ver con la oposición a un pensamiento sustancial, y (2) con la necesidad de superar el logos, también predicativo. Analicemos su relación con mayor detalle:

\footnotetext{
4 Panikkar, R., La puerta estrecha del conocimiento. Sentidos, razón y fe, Barcelona: Herder, 2009, p. 143.

5 Panikkar, R., The Intrareligious Dialogue, p. 33; Paz e interculturalidad. Una reflexión filosófica, p. 50 .

Panikkar, R., Paz e interculturalidad. Una reflexión filosófica, p. 49.

7 Cf. Gómez, C. M., "La hermenéutica intercultural de Raimon Panikkar", en: Franciscanum, c. LVII, 164 (2015), pp. 19-43.

8 Panikkar, R., Paz e interculturalidad. Una reflexión filosófica, p. 51.

9 Panikkar, R., The Intrareligious Dialogue, p. 33.

10 Panikkar, R., The Rhythm of Being. The Gifford Lectures, Nueva York: Orbis Books, 2010, p. 405.

11 Panikkar, R., Paz e interculturalidad. Una reflexión filosófica, pp. 34-35.

12 Ibid., p. 51.
} 
Respecto a la primera tesis parmenídea, Panikkar reclama la necesidad de superar el pensamiento sustancialista y predicativo, el cual considera antropomórfico: "El Ser no es primordialmente sustancia"13, sino que lo que hay es relación, función, que se despliega en un campo espacio-temporal. "La filosofia que ha superado el platonismo sabe bien que cuando especulamos sobre el amor, la voluntad, la libertad, no hablamos de sustancias, sino de relaciones" ${ }^{14}$. Por ello, "necesitamos nuevas categorias y un verdadero espíritu contemplativo" : un pensamiento funcional que "no elimina el pensamiento predicativo, pero lo pone en su sitio"16 es mucho más fructífero para expresar lo que hay. Por ello, la fenomenología, y no una metafisica de la sustancia, puede dar cuenta de esto de la mejor forma.

Panikkar considera que la ciencia moderna nos ha ayudado a ver esto al poner al descubierto "energías, procesos, acciones, efectos, etcétera, que no tienen consistencia sustancial" ${ }^{17}$, sino que son funciones. También repara en que el pensamiento cristiano ha ayudado a poner de manifiesto la importancia de la función, al considerar a Dios no como sustancia, sino como relación.

Sobre el ser característico de la función, dice Panikkar que debe ser considerado "en un 'sí mismo' relacional, es decir, en un campo" ${ }^{18}$, pues consiste en "una inter-in-dependencia mutua" ${ }^{19}$. "No podemos 'pensar' estas funciones en un esquema sustancial, sino en un marco espacio-temporal" ${ }^{20} \mathrm{y}$, en consecuencia, desde un punto de vista relacional. Lo mismo ocurre en un plano antropológico: "El hombre no es solo individuo: es persona, es decir, un nudo de relaciones que se extienden hasta los límites alcanzables por su alma" ${ }^{21}$. En esta línea, interpreta lo que significa ser santo en la tradición índica, o la afirmación de Aristóteles de que el alma es en cierto sentido todas las cosas, esto es, su identidad "es solo relacional" 22 .

Por tanto, el pensamiento funcional muestra la esencial conexión del ser, por una parte, y tiempo y espacio, por otra: "El pensamiento funcional penetra en el acaecer de las cosas, en cuanto que en cierto modo lo identifica con un fluir

\footnotetext{
${ }^{13}$ Panikkar, R., La puerta estrecha del conocimiento. Sentidos, razón y fe, p. 139.

14 Ibid., p. 140.

15 Ibid., p. 161.

16 Ibid., p. 143.

17 Ibid., p. 141

18 Ibid., p. 144.

19 Ibid., p. 141.

20 Ibid., p. 144.

21 Panikkar, R., Paz e interculturalidad. Una reflexión filosófica, p. 15.

22 Ibid., p. 16.
} 
temporal o lo refiere a un estar espacial" ${ }^{23}$. Esto es lo propio del pensamiento científico moderno, según Panikkar: "Espacio y tiempo son las 'formas' o las 'categorías' del pensamiento funcional. No por casualidad Kant quiso establecer un esquema conceptual para la ciencia" ${ }^{24}$, y no se pueden sustancializar, ni ontológica (Aristóteles) ni epistemológicamente (Kant).

Así pues, lo que opera en la revolución científica moderna es una transformación de las categorías con las que se desenvuelve el pensamiento. Por ello, hay que tomarse en serio la ciencia -dice Panikkar- ya que sus grandes éxitos "no se deben solo a su poder, por su alianza con la tecnología, sino también a haber 'tocado' un aspecto del saber filosófico, es decir, del conocimiento, olvidado por una cierta filosofia ('teorética')" ${ }^{25}$. En efecto, considera que con esta inversión categorial se logran resolver muchos de los problemas que nos desconciertan de la nueva física. A saber, desde la categoría de función: "resulta explicable que el electrón, por ejemplo, no esté en ningún lugar determinado, que sea representado como una onda, como una niebla o como una nube que circunda el núcleo. Si el electrón fuese un corpúsculo, esto sería inexplicable” ${ }^{26}$.

Sostiene que las paradojas "se manifiestan cuando interpretamos los datos de la ciencia con el pensamiento sustancial, en vez de aplicar el pensamiento más adecuado, el funcional ${ }^{27}$. Lo que no puede ocurrir, según el autor, es que haya cambiado la física y nosotros sigamos manteniendo la metafísica de antaño. Ambas van unidas: no pueden separarse si queremos dar cuenta integral de lo real y no fragmentarlo en ámbitos aislados.

Panikkar aclara este modo fundamental de ser asociado al pensamiento funcional a través de la distinción que establece entre la ex-istencia y la in-sistencia: las cosas no solo existen metafisicamente (es decir, frente a la nada), sino también espacio-temporalmente (son devenir, proceso), y esta dimensión es tan esencial como la propiamente metafísica, a pesar de haber sido relegada a segundo plano. En este punto se cifra el núcleo de la primera crítica que hace a Parménides: "El verdadero ser de las cosas no es solo su mero e-xistir (extra nihilum), sino también su complejo in-sistir (in tempore et spatio)" ${ }^{28}$, pues "el universo entero es un universo dinámico, en movimiento y gestación, en camino hacia una plenitud" ${ }^{29}$.

${ }^{23}$ Panikkar, R., La puerta estrecha del conocimiento. Sentidos, razón y fe, p. 144.

${ }^{24}$ Ibid.

${ }^{25}$ Ibid., p. 145.

${ }^{26}$ Ibid., p. 148.

${ }^{27}$ Ibid., pp. 147-148.

${ }^{28}$ Ibid., p. 146.

${ }^{29}$ Ibid., p. 147. 
Es decir, la espacialidad y temporalidad se reconocen como aquello que constituye al ser mismo, a toda la realidad: "Todo lo que existe se pone necesariamente en relación con las categorías espacio-temporales y con la materiaenergía de nuestro mundo" ${ }^{30}$. Así, "en este 'ser-siendo' es más importante el siendo que el llegar a ser. Ser es un verbo y en este verbo hay un camino espacio-temporal" ${ }^{31}$.

Pero esto no se aplica solo al ser creado, sino también al Creador, que se encarna y, en consecuencia, la temporalidad también le pertenece: no es ajeno a lo cósmico, es trinidad y, en consecuencia, relación. "La eternidad, entonces, no la podemos buscar al margen del tiempo, cayendo en las dicotomías de siempre, sino emergiendo de él por el descubrimiento de la realidad viviente que late en su interior" ${ }^{32}$.

A partir de esto, y en relación con la segunda crítica a Parménides, Panikkar deduce la insuficiencia originaria de cualquier sistema de pensamiento puramente conceptual como opus rationis, sea científico, filosófico o teológico, pues es por naturaleza abstracto y, como tal, estático, no contiene alusión alguna a determinadas circunstancias históricas. En referencia a una concepción ahistórica de lo divino, por ejemplo, considera que "un Cristo en sí y un cristianismo en sí independientes de toda referencia particular", "un sistema de salvación intemporal" y, en consecuencia, "incorruptible", es "completamente aséptico... pierde todo su sentido. La palabra pura, sustraída de todo contexto que pudiera darle un sentido particular, ya no le dice nada a nadie" ${ }^{33}$. Por ello, exige que el hecho religioso se viva desde el cuerpo, no desde un pensamiento espiritualista separador.

\subsection{El holismo cosmoteándrico}

Desde estas críticas a Parménides se puede entender la propuesta positiva del autor. Para él, la pregunta metafísica por el ser se responde diciendo que lo que hay es un "todo orgánico, indivisible a la vez que diferenciado", "la armonía de un cosmos sinfónico" ${ }^{\text {"35 }}$-y subraya la elección de la palabra "armonía"

\footnotetext{
30 Panikkar, R., "La visión cosmoteándrica: el sentido religioso y emergente del tercer milenio", en: Qüestions de Vida Cristiana, 156 (1991), pp. 78-102.

31 Panikkar, R., La puerta estrecha del conocimiento. Sentidos, razón y fe, p. 146.

32 Panikkar, R., "La visión cosmoteándrica: el sentido religioso y emergente del tercer milenio".

33 Vilanova, E., "Prólogo", en: Panikkar, R., La nueva inocencia, Estella: Verbo Divino, 1993, p. 13.

34 Panikkar, R., "La visión cosmoteándrica: el sentido religioso y emergente del tercer milenio".

35 Panikkar, R., La nueva inocencia, Estella: Verbo Divino, 1993, p. 337.
} 
frente a la "verdad", por ser esta "más cerebral" dimensiones últimas que, según él, componen lo real: lo cósmico, lo humano y lo divino que, como elementos distintos pero entrelazados, constituyen la sinfonía o el ritmo del ser. La vida es relatividad porque, como hemos visto, "la verdad misma es relacional" ${ }^{37}$ en su carácter funcional. Es decir, la realidad es, en su constitución o naturaleza unitaria, también trina, lo cual "es una constante de la cultura humana que encontramos por doquier: tanto en términos espaciales (cielo, tierra, ultratumba), como en los temporales (pasado, presente, futuro), e incluso en los cosmológicos o metafísicos (cuerpo, alma, espíritu)”" ${ }^{38}$. Es decir, forma parte de la experiencia humana de lo real más integradora, que Panikkar denomina cosmoteándrica.

El propio Panikkar califica su postura como cierto tipo de holismo desde su intención de superar los dualismos exclusivistas que la mente analítica occidental ha generado: "Superar no significa anular las diferencias, sino más bien trascender el pensar analítico, no con una síntesis que reúna los resultados del análisis, sino con un pensamiento holístico"39. Podemos denominarlo cosmoteándrico, pues, para él, constituye un "camino medio que se abre entre la paranoia del monismo y la esquizofrenia del dualismo" ". A saber, se trata de un holismo en el que, por una parte, aunque los elementos estén unidos y no puedan separarse, no se confunden en una eliminación por negación de todas sus diferencias, lo cual correspondería a un holismo total como el de Anaxágoras, o a un sistema monolítico por el que las cosas son meros modos de una única sustancia.

Panikkar se defiende, así, contra las acusaciones de holismo total y panteísmo a su pensamiento: sigue habiendo elementos que deben distinguirse, que son actualidades distintas y que, además, cabe contemplar desde innumerables perspectivas. Esta constituye precisamente la base para su tesis del pluralismo de la verdad. Insiste, en efecto, en que "es necesario evitar el uniformizar la compleja variedad del universo, pero no hay que temer buscar la relacionalidad de todas las cosas y hallar en ellas los vestigios de la misma Trinidad" ${ }^{41}$. Esta corresponde a su dimensión religiosa, "que nos 'religa' con toda

\footnotetext{
${ }^{36}$ Panikkar, R., Paz e interculturalidad. Una reflexión filosófica, p. 54.

37 Panikkar, R., La nueva inocencia, p. 327; Paz e interculturalidad. Una reflexión filosófica, p. 69.

38 Panikkar, R., "La visión cosmoteándrica: el sentido religioso y emergente del tercer milenio".

39 Panikkar, R., Paz e interculturalidad. Una reflexión filosófica, p. 13.

40 Panikkar, R., "La visión cosmoteándrica: el sentido religioso y emergente del tercer milenio".

41 Panikkar, R., La puerta estrecha del conocimiento. Sentidos, razón y fe, p. 153.
} 
la realidad, aunque sin dañar la ontonomía de todo ser" ${ }^{42}$. E1 “'caso' contiene en su interior una referencia constitutiva, una valencia abierta, una relación esencial con el todo" ${ }^{43}$.

Este tipo de holismo tampoco significa entonces, por otra parte, aislamiento, disgregación o desintegración de partes independientes que interactúan de forma puramente externa, sino por el contrario, su vinculación intrínseca, "interindependencia de las tres dimensiones de la realidad" como ritmo del ser ${ }^{44}$ o "relatividad radical" 45 . De hecho, según Panikkar, "las relaciones han de ser tan fuertes como los elementos que se ponen en relación", "aunque cada uno de ellos pueda ser abstraído y considerado independientemente por nuestra mente con finalidades tanto teóricas como prácticas" ${ }^{46}$. Solo así se evita un modelo pluralista atomista.

Es importante reparar en que la superación del dualismo que pretende Panikkar no implica la negación de lo característico de sus elementos, sino la comprensión de que cada uno de ellos por separado no agota el campo de lo real. En este punto se advierte el contraste entre su propuesta y otras como, por ejemplo, la del denominado "transhumanismo cultural" ${ }^{47}$, que aparentemente también persigue como objetivo dejar de lado las dicotomías de nuestro modo de manejar el mundo (natural/artificial, masculino/femenino, etc.), pero a costa de negar su especificidad.

Así pues, Panikkar formula un modelo de conocimiento basado en "una combinación de los dos principios [de no contradicción y de identidad], en la que la identidad no es anulada por la diferencia y la diferencia no queda absorbida por la identidad" ${ }^{48}$. Esta es la cualidad que caracteriza al conocimiento sapiencial, que nos hace "ver la visión de conjunto, integrando las aportaciones que las visiones parciales suponen para la globalidad" ${ }^{49}$.

La imbricación de las distintas dimensiones de lo real implica una afirmación de la presencia de cada una de ellas en las demás. Panikkar se refiere,

\footnotetext{
42 Ibid., p. 146.

43 Ibid., p. 146.

44 Manimala, V. J., "Raimon Panikkar, The Rhythm of Being: The Gifford Lectures. A Review Article”, en: Exchange, 40 (2011), p. 196.

45 Panikkar, R., "La visión cosmoteándrica: el sentido religioso y emergente del tercer milenio".

46 Ibid.

47 Cf. Velázquez Fernández, H., “¿Es la naturaleza humana modificable mediante la biotecnología? Transhumanismo: del perfeccionamiento ético al enhancement”, en: Naturaleza y Libertad, 10 (2018), pp. 347-372.

48 Panikkar, R., "La visión cosmoteándrica: el sentido religioso y emergente del tercer milenio".

49 Ibid.
} 
primero, a la sagrada secularidad como reconocimiento de la "dimensión divina de la realidad" ${ }^{50}$, que se aprecia en sus dos aspectos: tanto en su infinita trascendencia, "su carácter siempre abierto al misterio" como en su inmanencia, por su "profundidad insondable" e inmanipulable: "Todo ser tiene un fondo abismal, inasible e inconmensurable" ${ }^{\text {"1 }}$. Lo divino está en lo cósmico, corpóreomaterial. "Solo por ser realmente histórico, Jesús tiene un verdadero cuerpo, en el cual reside plenamente la divinidad" ${ }^{52}$, y en la subjetividad humana, "cualquier hombre (aun sin saberlo ni quererlo) ya no es ajeno a Cristo después de

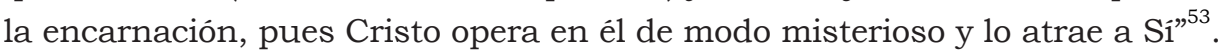

Esto exige, a juicio de Panikkar, una transformación de la teología para que no solo se ocupe de sí misma desde el uso privado de un lenguaje técnico entre los "funcionarios eclesiásticos", sino que "vuelva a encontrar las palabras sencillas" ${ }^{, 54}$ en la medida en que lo divino no es solo transcendente, sino también inmanente. El problema del mal no debe incomodar desde esta óptica, ya que la maldad es pura ausencia y, respecto a lo que es, "lo divino abraza la naturaleza entera", como afirma recogiendo las palabras de Aristóteles en la Metafisica ${ }^{55}$.

A su vez, como hemos visto anteriormente, la in-sistencia en el espacio y tiempo constituye a toda la realidad, por lo que la dimensión cósmica no es ajena tampoco a ningún objeto. Por último, la inter-independencia de los diversos aspectos de lo real significa que también se da una imbricación mutua de lo objetivo y subjetivo: "Debemos ser conscientes de que ningún problema es meramente objetivo y que todo planteamiento está hecho por $-\mathrm{y}$ referido a- sujetos determinados, a los que les afecta de un modo particular", de igual modo que "todas las cosas quedan humanizadas al entrar en la esfera de nuestro conocimiento" ${ }^{, 56}$. En consecuencia, en ninguno de los dos sentidos es posible hablar de neutralidad respecto a nuestro conocimiento, porque este nos afecta y afecta a las cosas. No hay, pues, razón pura, "no contaminada por las impurezas de cualquier contacto con el resto del hombre, es decir, el cuerpo, los sentimientos, el amor..." ${ }^{57}$, ni la realidad "es solo una realidad a

$324{ }^{50}$ Manimala, V. J., "Raimon Panikkar, The Rhythm of Being: The Gifford Lectures. A Review Article", en: Exchange, 40 (2011), p. 197.

${ }^{51}$ Panikkar, R., "La visión cosmoteándrica: el sentido religioso y emergente del tercer milenio".

52 Cirlot, V., Melloni, J., Tamayo, J. J. y J. I. Saranyana, "2018, el año Panikkar", El Ciervo: revista mensual de pensamiento y cultura, 279 (2018), p. 19.

${ }^{53}$ Ibid., p. 19

${ }^{54}$ Vilanova, E., "Prólogo", p. 11.

55 Panikkar, R., La puerta estrecha del conocimiento. Sentidos, razón y fe, p. 153.

${ }^{56}$ Panikkar, R., "La visión cosmoteándrica: el sentido religioso y emergente del tercer milenio".

57 Panikkar, R., Paz e interculturalidad. Una reflexión filosófica, p. 55. 
se, objetiva; está también en nosotros, subjetiva; formamos parte de ella" Así pues, Panikkar se propone como objetivo superar "la grieta epistemológica entre sujeto y objeto que nos aboca al dilema insuperable entre el idealismo y el realismo" 59 . Al situarse un paso más atrás que la relación de objetivación del logos -"el objeto (ob-jectum) es lanzado como un misil en una incursión estratégica sobre territorio extranjero", dice ${ }^{60}-$, se ofrece una perspectiva más amplia de lo real que da cabida a otras experiencias humanas de ello que no lo contemplan meramente como objeto.

\section{La metafísica de la sustancia como forma substantialis o el holismo sus-} tancial de Fernando Inciarte

\subsection{La necesidad de la sustancia como principio de distinción}

Inciarte responde a la pregunta metafisica primordial diciendo que la sustancia es lo que es en sentido primario o fundamental. Sostiene que es necesario admitirla como reconocimiento de que hay entidades diversas en la realidad, que no todo es lo mismo, de modo que existe una distinción neta entre una cosa y los hechos en que esta ocurre, entre ella y lo que se predica sobre ella, entre significar y significar "de" o "acerca de", de forma que el predicado no participa en la constitución del sujeto. De otra manera, si esto ocurriera, no habría auténticas distinciones entre las cosas y, en consecuencia, no sería posible decir nada falso. Allaire ${ }^{61}$ apunta a una distinción semejante al referirse a la inexistencia de una conexión lógica entre lo que es una cosa y los hechos en que se da.

El reconocimiento de la sustancia es lo que permite mantener de forma consistente el principio de no contradicción (PNC) según Inciarte ${ }^{62}$, pues sin ella se procede al infinito, se predica todo de todo. El autor manifiesta que la deducción del PNC como primer principio cognoscitivo que Aristóteles lleva a cabo en la Metafisica y que establece las condiciones necesarias para el razonamiento, el lenguaje y la comunicación, coincide con la deducción trascendental de las categorias en general y de la sustancia en particular como primer principio ontológico.

\footnotetext{
58 Ibid., p. 71.

59 Panikkar, R., "La visión cosmoteándrica: el sentido religioso y emergente del tercer milenio".

60 Panikkar, R., Paz e interculturalidad. Una reflexión filosófica.

${ }^{61}$ Cf. Allaire, E. B., "Existence, Independence and Universals", en: Allaire E. B. (ed.), Essays in Ontology, La Haya: Martinus Nijhof, 1963, pp. 1-13.

${ }^{6}$ Cf. Inciarte, F., First Principles, Substance and Action. Studies in Aristotle and Aristotelianism, Hildesheim/Zürich/Nueva York: Olms, 2005.
} 
En concreto, detecta varios pasos en el razonamiento aristotélico relativo al PNC que pueden hacerse corresponder con comprensiones progresivamente más completas de la sustancia en lo que pueden considerarse como sendos procesos paralelos de deducción: solo cuando se alcanza el último paso puede mantenerse de manera plena el PNC. Estos pasos son los que se presentan a continuación.

Primero, se refiere a la necesidad de admitir una pluralidad de palabras con diferentes significados y, en correspondencia, diferentes categorias, de modo que cada palabra tiene un solo significado -o un número limitado de ellos-, pero no todos los demás: no todo significa todo. Sin embargo, estos significados "no tienen nada en absoluto en común entre sí... no están qua significados relacionados de ninguna manera uno al otro" ${ }^{\text {"63 }}$. Solo pueden ser pensados en una relación per accidens. Esto es, en este momento "uno no ha detectado todavía ningún orden o reglas para relacionar un significado a cierto otro en vez de todavía a un tercero o diferente significado" ${ }^{64}$, puesto que no están relacionados a priori o por definición.

En segundo lugar, para llevar a cabo esta conexión, que no es aleatoria, se percibe la necesidad de admitir un principio ontológico, la sustancia como sujeto real de propiedades. Esto es así porque ella establece un orden entre aquellos significados en tanto que solo ella puede funcionar como sujeto de predicaciones y no los accidentes mismos. Ella posibilita la unidad, pues sin ella habria series infinitas de accidentes: "Si todas las afirmaciones son accidentales, no habrá nada primario acerca de lo que ellas (estas afirmaciones) sean... La predicación, entonces, debe continuar ad infinitum. Pero esto es imposible”65.

Sin embargo, Inciarte observa, en tercer lugar, que, si se admite la sustancia comprendiéndola solamente como puro sustrato indeterminado de propiedades accidentales, aún no se logra mantener de manera plena el PNC, ya que "todavía no habría ninguna regla o ningún criterio (más allá de decir que los accidentes han de serlo de una sustancia) para relacionar los accidentes con unas sustancias en lugar de con otras" ${ }^{\prime 66}$, de modo que todos los accidentes podrian relacionarse con todas las sustancias. Además, en último término solo podría admitirse la existencia de una sola sustancia, dado que, para que pueda admitirse una pluralidad de ellas, es necesario que cada una posea su propia

63 Ibid., p. 54.

64 Ibid., p. 55.

65 Ibid., p. 46.

66 Espinosa, Z., Percepción, pensamiento y lenguaje. El realismo radical de Reinhardt Grossmann y el realismo moderado de Fernando Inciarte, Pamplona: EUNSA, 2015, p. 56. 
esencia. De aquí concluye la necesidad de entender la sustancia no solo como particular desnudo, sino como esencia para dar cuenta de que solo ciertas cosas (accidentes) están conectadas a ciertas otras (sustancias). La esencia proporciona el criterio para relacionar únicamente ciertas propiedades con ciertas cosas en lugar de con otras, de modo que no puedan predicarse de la misma sustancia dos predicados contradictorios.

Por tanto, Inciarte argumenta cómo es necesario admitir las sustancias como esencias para poder mantener de forma consistente el PNC: únicamente se corta el paso a la predicación de cualquier cosa de cualquier otra cuando, en primer lugar, no todo es lo mismo, sino que se distingue entre una cosa (sujeto) y lo que se dice de ella (predicado), y cuando, en segundo lugar, se identifica la sustancia con la esencia, que constituye la referencia para determinar qué predicaciones le convienen y cuáles no.

Si se prescinde de la sustancia se desemboca en una posición metafísica holista que "elimina conceptos, significados, definiciones, o categorias" ${ }^{, 67}$ y que "lleva a una forma de caos en la que todo está en todo ${ }^{68}$. Ciertamente Inciarte reconoce que lo que en cada caso concreto se determine como sustancia es en cierta medida -pero no completa o totalmente- cultural y lingüístico. Se pregunta: “¿Son sustancias los minerales o más bien las moléculas de que se puedan componer, o los átomos de que estas se compongan de esta o la otra manera, o las partículas de que los átomos se puedan componer de esta o de la otra manera?" ${ }^{69}$. Y responde que "por supuesto que... hay un margen de indeterminación para saber dónde empieza una montaña. Pero esto no impide que 'montaña' como concepto abstracto (como 'cualidad' en el sentido hegeliano, o como 'idea' en el sentido platónico) sea de un modo o de otro definible, delimitable, y pueda actuar así como criterio de identidad" ${ }^{70}$.

Defiende que deben poder reconocerse distintas unidades de sentido de las que pueda hablarse como sujeto de las proposiciones. De otro modo, no se sabria de qué se está hablando. Precisamente por la dificultad de determinar a ciencia cierta si algo concreto es una sustancia o no, sostiene que Aristóteles "daba una importancia mayor a la pregunta sobre si, primero, tenemos que

\footnotetext{
${ }^{67}$ Inciarte, F., First Principles, Substance and Action. Studies in Aristotle and Aristotelianism, p. 61.

${ }^{68}$ Ibid., p. 60.

${ }^{69}$ Inciarte, F., Cultura y verdad, Pamplona: EUNSA, 2016, p. 200.

${ }^{70}$ Ibid., p. 96.
} 
aceptar sustancias en general y, segundo, sobre qué significa ser sustancia que a la pregunta sobre qué cosas son sustancias" ${ }^{, 11}$.

Desde esta perspectiva, la transformación que implica la revolución científica no puede ser para Inciarte tan profunda como para eliminar la necesidad de reconocer la sustancia como aquello que propia o primariamente existe. El pensamiento sustancial no es, según Inciarte, histórico o cultural, es decir, dependiente del sujeto o de sus modos de conciencia, sino que es estrictamente metafisico, es decir, pegado a la realidad de las cosas. No constituye meramente una aproximación al ser en tanto que revestido por las estructuras lógico-lingüísticas o ideales de la mente: "Lo único metafísicamente real.... es la sustancia que está constantemente cambiando y es, por tanto, ajena al carácter abstracto de la conciencia” ${ }^{72}$. Todo lo demás, las estructuras, los conjuntos, los hechos, los accidentes, los estados, son relativos a la conciencia, no subsisten por sí mismos, pues requieren la mediación de la conciencia para existir.

Es decir, esta necesidad -de admitir la sustancia y, paralela o correspondientemente, el PNC- no tiene que ver solo con nuestro modo de acceder al mundo. A diferencia de lo que Panikkar parece dar a entender, el PNC no se entiende como un principio meramente lógico, de la limitada mente humana, sino que rige en el plano ontológico. Si hay sustancia, no todo es lo mismo: el PNC se cumple en la realidad. Y, en la medida en que para Inciarte la deducción del principio de no contradicción como principio cognoscitivo y el de la de la sustancia como principio ontológico coinciden, o constituyen dos caras de la misma moneda, no subraya de forma tan aguda como Panikkar la insuficiencia del pensamiento -entendido en sentido amplio, no solo natural- para dar cuenta de lo real. En cambio, las propias condiciones de posibilidad del logos conducen a la identificación de un principio real: la sustancia. No se trata aquí de que Inciarte vaya a defender un paralelismo entre lo real y lo ideal, pues no lo hace, como se verá más adelante, pero no entiende el ser como algo que está más allá de las reglas básicas del logos, si bien sí reconoce la limitación estructural de la racionalidad predicativa de las lenguas indoeuropeas.

\footnotetext{
${ }^{71}$ Ibid., pp. 199-200.

${ }^{72}$ Espinosa, Z., "¿'Sustancias o hechos? La entidad fundamental de una teoría de las categorias", en: Anuario filosófico, v. XLVII, 2 (2014), p. 445.
} 


\subsection{El significado del holismo sustancial: la inexistencia de los accidentes y los estados}

La tesis de que la sustancia es lo que es en sentido primario muestra todo su alcance en la afirmación de que ella es, estrictamente hablando, lo único que existe, lo único metafisicamente real, y esto significa que no existen propia o realmente ni los accidentes ni los estados, lo cual supone un rechazo a determinadas ontologias. Veamos ambas cosas en detalle.

Por una parte, Inciarte sostiene que los accidentes de las cosas no son nada de suyo, según la tesis aristotélica de Metafisica, 1030a 21-27, de que "los accidentes en realidad -literalmente, en la realidad- no existen". Es decir, a parte rei, no les corresponde ningún ser, ni tan siquiera disminuido o más débil -inherencia- frente a la subsistencia. Por tanto, no existen dos cosas, sustancia $y$-además- accidentes, sino una sola, que puede ser contemplada desde distintos puntos de vista: en tanto que se considera su permanencia o desde su variabilidad. Los accidentes son meramente "los cambiantes estados en que una sustancia puede existir ${ }^{\text {,73 }}$, su dimensión potencial o cambiante. Así pues, "no hay más diferencia entre ellos [sustancia y accidentes] que la que hay entre la carretera que va de Tebas a Atenas y la que lleva de Atenas a Tebas" ${ }^{74}$. Esto es, puede hablarse de una identidad real, en el orden ontológico, entre ellos (que puede ser necesaria o contingente, en función de si se trata de propiedades esenciales o accidentales), y esta constituye su tesis original del holismo sustancial. Sobre esta base, la analogía del ser que se da entre el ser de la sustancia y el de los accidentes no es una analogía según el ser y según la intención, sino solo una analogía según la intención, para la que "el ser de los accidentes es el ser de la sustancia y nada más"75.

Inciarte considera que el sentido principal de sustancia es la forma sola (individual), no la materia ni el compuesto de materia y forma (forma essentialis), apoyándose en la tesis aristotélica de Metafisica, 1035b 26 de que "ningún universal es sustancia", "hombre y caballo y todo lo que de este modo se aplica a los individuos, pero universalmente, no es una sustancia, sino un compuesto de materia y forma". De la forma caben dos interpretaciones posibles que

\footnotetext{
${ }^{73}$ Inciarte, F., First Principles, Substance and Action. Studies in Aristotle and Aristotelianism, p. 188. Inciarte, F., "Anhang", en: Hüntelmann, R. y E. Tegtmeier (eds.), Neue Ontologie und Metaphysik, Sankt Augustin: Academia, 2000, p. 170.

${ }_{74}$ Inciarte, F., First Principles, Substance and Action. Studies in Aristotle and Aristotelianism, p. 137.

75 Ibid., p. 51.
} 
corresponden a distintos niveles de reflexión sobre ella: como forma (desde la perspectiva de los contenidos) y como acto (desde la perspectiva de la modalidad).

El enfoque categorial o de contenidos concibe la forma como forma essentialis, como especie que incluye también la materia, por lo que acaba entendiendo la sustancia como un compuesto. Desde su perspectiva analítica, comprende las diversas determinaciones de la cosa como si fueran independientes antes de su composición, algunas fuera y sobre las otras, como partes extra partes en un esquema vertical y con un significado univoco. Esta perspectiva corresponde a la visión platónica de un ultrarrealismo estricto de los universales, que es sustancialista o reísta en la medida en que traslada al orden real el modo de ser de las formas en el plano ideal, desde la creencia en un isomorfismo o paralelismo entre ambos planos.

Pero, si se adopta un punto de vista funcional o modal, interpretando la forma como acto, se observa que las distintas formalidades no existen separadas en la realidad, no son unidades discretas externas unas a otras, distintas a parte rei, pues las propiedades no son en ningún sentido partes. El género, por ejemplo, no puede existir al margen de la diferencia específica, ni la sustancia sin accidentes, ni la materia sin forma, sino que son la misma cosa observada desde distintos puntos de vista: según su aspecto potencial, su capacidad de cambio, o según su aspecto actual o de realidad. Las diversas determinaciones de una cosa no tienen lugar en ella como capas independientes e inalteradas, sino que se modifican mutuamente y, en consecuencia, aparecen en una manifestación especial en cada tipo de ser: su relación no es meramente lógica, sino metafísica. No existen, en consecuencia, de manera unívoca, sino análoga, pues no puede tomarse una característica común a varios tipos de cosas de la misma manera. Lo ejemplifica de la siguiente manera: "la justicia no se da de la misma manera en los sujetos que la presentan, sino modificada en referencia al individuo mismo de que se trate y a sus demás propiedades, por ejemplo, el resto de sus virtudes" ${ }^{, 76}$.

Este enfoque supone una superación del dualismo que lleva a la disgregación, a un atomismo del que sigue siendo presa en gran medida el pensamiento metafisico actual, limitado en muchos planteamientos a su aspecto ontológicocategorial y, por tanto, basado en la representación de la composición. Esta superación del dualismo se posibilita en la perspectiva funcional porque en ella se entiende que la esencia de la sustancia es únicamente la forma subs-

\footnotetext{
${ }^{76}$ Espinosa, Z., "La identidad del sujeto individual a través del modelo de la sustancia: un contraste entre F. Inciarte y R. Grossmann", en: Pensamiento y cultura. Revista de Filosofia, v. XVI, 1 (2013), p. 63.
} 
tantialis, que es la forma individual que excluye la materia. Sin embargo, esto no supone prescindir de los accidentes o de la dimensión cambiante de las cosas siempre y cuando la forma se interprete, desde la perspectiva modal, como su acto, puesto que entonces la abarca como su potencialidad. Esta es la virtualidad que tiene para Inciarte la contemplación de la forma no meramente como contenido, sino desde el punto de vista de la modalidad. Cuando esta se interpreta de esta manera, como acto, contiene el todo en sí misma y "de la manera más alta posible, en su mayor grado de unidad, como un todo unido" ${ }^{77}$, en tanto que su realidad.

Desde la comprensión de la última forma como acto "resulta errada toda búsqueda de un elemento unificante que sea una tercera 'cosa' entre las otras $^{, 78}$, no se necesita una relación ulterior que una esta forma al resto de determinaciones de la cosa -del mismo modo que el pegamento pega sin necesidad de que sea él mismo pegado a cada uno de los elementos que relaciona-, sino que es, por definición, actualidad o realidad "de" un elemento potencial. Está referida a otro, a una materia que es según la posibilidad lo que la forma es según la realidad, al igual que los accidentes, como dimensión potencial de la sustancia, son siempre accidentes "de" (una sustancia) y si, por el contrario, tuvieran ser por sí mismos, se daría una reduplicación y regresión al infinito.

Así pues, no hay, por un lado, los elementos (materia y forma, por ejemplo, accidentes y sustancia, homo y esse) y-además-su relación, sino "elementos en relación" (esse hominis): "Si la constitución metafísica de la sustancia implicara una amalgama de partes espaciales o temporales, entonces el compuesto real o (en una definición lógica) ideal no sería nunca capaz de formar una unidad de propiedades" ${ }^{\prime 79}$. Es decir, "desde este planteamiento dualista de la composición [que es propio del enfoque categorial o de contenidos], y por muchas entidades adicionales (por ejemplo, relaciones) que se hagan intervenir en el análisis ontológico para conectar lo que está ahí ya, se vuelve imposible de raíz fundamentar adecuadamente la unidad de los entes" ${ }^{80}$.

Precisamente por este motivo se observa que no pueden existir tampoco, por otro lado, los estados, partes o fases espacio-temporales como unidades

\footnotetext{
${ }^{77}$ Espinosa, Z., “¿Esencia y nominalismo? Algunas críticas y respuestas en torno a la noción de esencia", Acta Philosophica, v. XXIV, 1 (2016), p. 101.

${ }_{79}^{7}$ Ibid., p. 101.

${ }^{79}$ Inciarte, F., First Principles, Substance and Action. Studies in Aristotle and Aristotelianism, p. 146.

${ }^{80}$ Espinosa, Z., “¿'Sustancias o hechos? La entidad fundamental de una teoría de las categorías”, en: Anuario filosófico, v. LXVII (2), 2014, p. 418.
} 
ontológicas, es decir, estados compuestos de la sustancia y alguno de sus accidentes, por ejemplo, "Sócrates sentado", o "el estar de Juan en la escuela en t1", que se encuentren en una relación de sucesión temporal de modo que se van sustituyendo unos a otros, como cuando "el estar de Corisco en el mercado sigue al estar de Corisco en el liceo" ${ }^{81}$. Esto corresponde a una ontología de procesos o eventos que Inciarte detecta en Quine, propia de la concepción empirista de la mente como proceso o estructura temporal, y que también se ajusta a la ontología de la ciencia moderna, en la que los fragmentos espacio-temporales se consideran las unidades fundamentales de la realidad.

Sin embargo, sostiene Inciarte que en este planteamiento se pone en peligro el PNC, pues el predicado formaría parte de la constitución del sujeto, este no significaría una sola cosa (o un número limitado de ellas) y entonces no podría decirse nada falso. Además, estos estados no pueden existir en la realidad, pues son meras abstracciones "de un estado contingente que comprende a este, así como a muchos otros accidentes" ${ }^{\prime 2}$. Es decir, son abstracciones a partir de lo único que existe, que es la sustancia cambiando continuamente.

En definitiva, como vemos, Inciarte destierra varias comprensiones de lo que verdaderamente hay, de lo que metafisicamente existe, a las que considera equivocadas, que corresponden con distintas maneras insuficientes de entender la sustancia: (1) En primer lugar, rechaza la comprensión de la sustancia como mero particular desnudo o puro sustrato de propiedades accidentales porque, entre otras cosas, no permite mantener de forma cabal el PNC ya que, concebida así, no ofrece ningún criterio para admitir como propiedades suyas ciertos accidentes y no otros, por lo que todos los accidentes podrían relacionarse con todas las sustancias. (2) En segundo lugar, objeta a la ontología de procesos su visión de los individuos como suma o sucesión de estados espacio-temporales por un motivo semejante: porque en estos estados se pone en peligro el PNC al introducir el predicado en el significado del sujeto y, además, porque de un compuesto tal de elementos sucesivos no puede resultar ninguna verdadera unidad. Y, por último, (3) rehúye de la concepción de la sustancia como compuesto de materia y forma (forma essentialis) porque es presa de un planteamiento dualista que no permite dar cuenta de la unidad de los seres. Según él, para llegar a una interpretación adecuada de lo que existe, hay que eliminar todo tipo de compuestos: tanto los estados ("hombre blanco"), como

81 Inciarte, F., First Principles, Substance and Action. Studies in Aristotle and Aristotelianism, p. 285 .

82 Ibid., p. 285. 
los compuestos esenciales ("hombre"), ya que estos abarcan todavia una suma de elementos. Es necesario llegar a puras formas, por ejemplo, el alma como actualidad del cuerpo orgánico.

Por tanto, a la pregunta por lo que realmente existe, Inciarte responde diciendo que existe la sustancia entendida como la forma sola. Cuando esta se interpreta, además, como acto, se logra dar cuenta de:

(1) La identidad de la cosa a lo largo del tiempo, pues la forma la representa en tanto que permanece, en tanto que es la misma a través de los cambios -sujeto de ellos-. En función de cómo se interprete, da cuenta de la permanencia en la misma especie-eidos como forma essentialis o species-, o de la permanencia de cierta materia como el mismo individuo a través de los cambios -eidos como forma substantialis-.

(2) La unidad con la que se nos aparecen las cosas, pues la forma interpretada como acto aporta el sentido superior o más alto de unidad, por encima de la unidad de sucesión (ya sea de contigüidad o consecutividad de cosas que están unas detrás y fuera de las otras) o de la unidad de continuidad de partes espacialmente extendidas (que es una unidad puramente material, por lo que no se contempla la cosa verdaderamente como unidad, sino como una diversidad de partes y, por ello, no sirve para dar cuenta de la dimensión funcional de las cosas).

Como hemos visto, la forma como acto abarca en sí todo el resto de determinaciones como posibilidad a la manera de un sistema de sistemas, de una forma formarum (1970) a la que Aristóteles ya alude en De anima: "De donde resulta que el alma es comparable a la mano, ya que la mano es instrumento de instrumentos y el intelecto es forma de formas, así como el sentido es forma de las cualidades sensibles" ${ }^{\prime 83}$. Esto es, unifica en sí todas las formas y las representa en el sentido más comprehensivo y unitario: en tanto que constituye su realidad o actualidad, sin necesidad de ser ella misma relacionada a las demás. Desde este punto de vista modal, la realidad se comprende como realidad de, referida a otro y, en consecuencia, intrinsecamente relacional.

4. La relación entre ambos planteamientos: ¿dos metafisicas de sistema?

A pesar de las apariencias que separan a primera vista a ambos pensadores (la defensa de una metafísica de la sustancia por parte Inciarte, frente a una crítica a ella desde una teofisica de la relación, en la propuesta de Panikkar),

${ }_{83}$ Aristóteles, Metafisica, Madrid: Gredos, 1994, pp. 241-242. 
tanto uno como otro reivindican la necesidad de superar un pensamiento puramente categorial, centrado en los contenidos como forma de pensamiento predicativo. Para ambos autores este presenta dos limitaciones estructurales que revelan su carácter onto-lógico, es decir, más lógico que estrictamente metafísico o, en palabras de Panikkar, su carácter abstracto:

(1) Por un lado, el pensamiento categorial-predicativo prescinde del tiempo, se sitúa en una perspectiva sincrónica o atemporal, dirige su atención a las entidades en una sección del tiempo y, por tanto, al margen de él, desde la tendencia "destemporizadora y espacializadora" ${ }^{84}$ propia de la conciencia, de modo que queda fuera de su consideración el carácter histórico, dinámico y cambiante de los entes.

(2) Por otro, da lugar a una comprensión no unitaria de los entes -como compuestos- y, por tanto, lleva a un dualismo, a una escisión irreparable en el ser.

Por tanto, desde el planteamiento de Inciarte se aprecia la relación que se da entre el sentido del ser según las categorias y el sentido del ser veritativo. En la concepción de Panikkar, las categorias también tienen una validez más bien mental o lógica, puesto que constata que varían tremendamente de una cultura a otra: "Éste es el gran poder y la gran tentación de la mente humana: el gran poder del pensamiento conceptual abstracto y la tentación de identificar el pensamiento con la abstracción, haciendo así del pensar un puro cálculo entre datos abstractos" $"$.

Inciarte denuncia nuestra tendencia logicista, que se ha agudizado desde los comienzos de la modernidad, por la que aplicamos a lo real aquello que es característico del modo de ser de lo mental, imponemos "estructuras conceptuales o lingüísticas a la realidad" ${ }^{, 86}$ ), de modo que acabamos convirtiendo la metafísica en lógica o semántica y nos acabamos ocupando de la realidad que nosotros mismos hemos producido. Panikkar dice en el mismo sentido: "El pensamiento conceptual es como un andamio que nos permite construir un edificio sólido, pero el andamio no es el edificio y menos aún hemos de confundir este edificio con toda la realidad" ${ }^{87}$.

\footnotetext{
84 Inciarte, F., Tiempo, sustancia, lenguaje. Ensayos de metafisica, p. 102.

85 Panikkar, R., Paz e interculturalidad. Una reflexión filosófica, p. 41.

${ }^{86}$ Inciarte, F., First Principles, Substance and Action. Studies in Aristotle and Aristotelianism, p. 128 .

87 Panikkar, R., Paz e interculturalidad. Una reflexión filosófica, p. 42.
} 
En efecto, nos inclinamos a pensar que las diversas determinaciones de las cosas se dan en la realidad:

-separadas unas de otras, como si fueran partes. Sin embargo, la distinción que se da entre las formas no corresponde a la distinctio a parte rei de Escoto, sino a la distinctio rationis cum fundamento in $r^{88}$. Panikkar ${ }^{89}$ se refiere a la "obsesión analítica de la época moderna" y sostiene sobre ella que "la clasificación implica la convicción de que la realidad puede dividirse en partes individualizables de manera homogénea -sean personas, átomos o cualquier cosa-" ${ }^{90}$.

- con una existencia unívoca. Sin embargo, esta es propia únicamente de lo mental, ya que en la realidad la misma determinación aparece de modo en parte igual, pero también en parte diferente en cada tipo de ser, con relación a sus otras determinaciones. Es decir, su relación con estas no la deja inafectada, sino que la modifica en parte.

Este trasvase de lo ideal a lo real a partir de la idea de un isomorfismo ente ambos planos, es propio del pensamiento sustancialista o reísta que concibe la sustancia de forma errónea como un sustrato espacial, desde la representación burda que la imaginación puede aportar de ella. Esta comprensión inadecuada es la que origina las críticas más habituales al planteamiento esencialista, por lo que Inciarte considera que estas deben ser revisadas a la luz de un correcto análisis de la sustancia.

Precisamente estas dos cosas que Inciarte objeta a esta concepción sustancialista en sentido negativo son también las que Panikkar denuncia en nuestra forma de abordar lo real: para él lo divino, lo cósmico y humano no se dan como instancias separadas unas de otras; esto solo ocurre así en la mente, que necesariamente tiene que proceder distinguiendo. Tampoco existen univoca, sino análogamente. Por ejemplo, lo divino se manifiesta espacio-temporalmente, por lo que también es inmanente, al igual que lo cósmico resulta ser humano al entrar en el alcance de su conocimiento y, lejos de permanecer neutral, queda afectado por ello.

La insistencia de Inciarte en la necesidad de superar el enfoque ontológico-categorial de la composición y, por tanto, del dualismo, es, si bien no tan explícita como en el pensamiento de Panikkar, uno de los puntos centrales

\footnotetext{
${ }^{88}$ Cf. Inciarte, F., First Principles, Substance and Action. Studies in Aristotle and Aristotelianism, p. 116.

${ }^{89}$ Panikkar, R., Paz e interculturalidad. Una reflexión filosófica, p. 26.

${ }^{90}$ Ibid., pp. 41-42.
} 
de su metafísica. Frente a Panikkar, Inciarte no niega la validez o la utilidad, dentro de cierto ámbito, del pensamiento categorial, centrado en los contenidos, pero exige que se reconozcan distintos niveles de reflexión, y considera que el más profundo de ellos (por no ser meramente lógico, sino presentar las cosas tal como son en la realidad) se alcanza cuando se supera el enfoque categorial o sustancialista hacia la perspectiva de la modalidad.

Inciarte advierte, como Panikkar, el carácter abstracto o lógico de toda ciencia. Pero él sitúa la metafísica como ontología trascendental como una excepción al pensamiento científico, en la medida en que cree que ella es la única disciplina que se esfuerza por traer a la presencia lo real como tal, el ens qua ens, y no en tanto que pensado. Por eso estima que "en el caso de una metafísica considerada como una teoría de los principios este riesgo [nuestra tendencia logicista] no está presente" ${ }^{\prime 1}$. Para ello hace una distinción entre la metafísica como doctrina de los primeros principios y la mera ontología, que sí se acerca a lo que hacen otras ciencias particulares, con su espíritu clasificatorio de conceptos con contenidos univocos.

Sin embargo, para Panikkar toda forma de pensamiento (también el metafísico y teológico) viene marcada por esta tendencia abstracta, de la que no puede desembarazarse en tanto que pensamiento. Para él, cualquier teoría adolece de una limitación estructural e insuperable, puesto que ningún pensar agota la libertad del ser. Y, por ello, es necesario otro lenguaje, unas "palabras verdaderamente humanas", que "son más que signos y mucho más que conceptos" ${ }^{\prime 2}$ : el lenguaje de la intuición o místico que recurre a los simbolos, que son relacionales, logran conectar, frente al aislamiento del concepto. Por ello, solo a través de este medio como forma superior de entendimiento puede lograrse una aproximación holística a lo real, necesaria para captarlo de forma comprehensiva.

Inciarte también repara en la necesidad de otro lenguaje distinto al predicativo para expresar la modalidad, pues aquel está ligado al sustancialismo y se queda corto para expresar un ser que es pura actividad autosubsistente, sin sujeto, un puro ser verbal. La mente humana, que es actualidad mezclada con potencialidad, no puede comprender el Acto puro, por lo que hay una semejanza notable entre ambos autores en este aspecto. No obstante, Panikkar dedica un esfuerzo mucho más notable a destacar la necesidad de una nueva forma

\footnotetext{
91 Inciarte, F., First Principles, Substance and Action. Studies in Aristotle and Aristotelianism, p. 128 .

92 Panikkar, R., Paz e interculturalidad. Una reflexión filosófica, p. 67.
} 
de conciencia que sea superadora de la racionalidad occidental hegemónica moderna.

Ambos autores reclaman, por tanto, en último término, lo mismo: la necesidad de superar el pensamiento sustancialista-que ha fragmentado o dividido el ser- hacia uno funcional, prescindiendo de los caracteres morfológicos en favor de los funcionales. Es decir, los dos quieren pasar de la forma (contenido) a la función (relación) para dar cuenta de lo real de forma más ajustada. Este pensamiento funcional corresponde con un pensamiento relacional, en tanto que la función se da en un campo espacio-temporal, como afirma Panikkar, y remite a otro (para Inciarte, la forma como acto se comprende desde su función de actualización, vivificación o realización, que es de otro, tiene lugar respecto $a$ otro).

Esto es, la perspectiva modal que Inciarte adopta en el último y fundamental paso de su razonamiento, por la que interpreta los elementos constitutivos de los seres en tanto que acto y potencia, constituye en sí misma un punto de vista relacional semejante al que Panikkar está exigiendo. En efecto, la semejanza entre el acto y la relación es notoria porque, por un lado, el principio actual "relaciona o unifica en sí mismo todas las formas de una entidad sin necesidad de ser él mismo relacionado a ellas"93. Por otro lado, lo mismo ocurre con las relaciones: "No necesitan estar relacionadas por otra entidad a aquello que conectan" "94 , a través de lo que constituiria una relación de segundo grado, pues, si no, se procedería al infinito.

Por tanto, cuando se entiende la última forma como acto, en la medida en que este abarca todos los demás constitutivos del ser como su potencialidad, se puede decir que forma y materia no son cosas distintas, no son algo otro, sino que se atraviesan mutuamente. En su tesis del holismo sustancial, Inciarte hace una superación del sustancialismo como un tipo de pensamiento dualista que está en la dirección en que Panikkar apunta: no hay dos cosas, sustancia y accidentes de forma independiente, sino una sola: la sustancia que se transforma.

Es decir, desde el punto de vista modal, no de los contenidos, Inciarte está afirmando la identidad real de materia y forma. Extrapolando esto mismo a la triple naturaleza de lo real -divino, cósmico y humano- llegamos a la

\footnotetext{
${ }^{93}$ Espinosa, Z., “¿Esencia y nominalismo? Algunas críticas y respuestas en torno a la noción de esencia”, p. 102.

${ }^{94}$ Grossmann, R., The Categorial Structure of the World, Bloomington: Indiana University Press, 1983, p. 167.
} 
tesis de Panikkar del holismo cosmoteándrico. Así pues, si en Inciarte "toda la sustancia... está en cada uno de sus accidentes" "95 y en cada uno de estos se encuentra la sustancia entera ("en el movimiento de un móvil está todo el móvil" y "en el movimiento que hace mi mano para escribir estas líneas está todo mi yo, todo mi ser" ${ }^{96}$ ), y en un acto de caridad "entran todas las demás

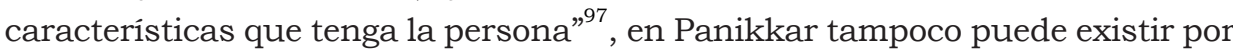
separado cada una de las dimensiones de la vida. Así no se niega ni se elimina ninguno de estos elementos, sino que se conservan en tanto que dimensiones distintas de lo único real. Toda distinción que los dote de ser independiente es obra del pensamiento.

Si Inciarte considera que "desde el punto de vista ontológico hay una prioridad de la unidad, de la interdependencia de las formas frente a su consideración por separado en una especie de esquema vertical" ${ }^{98}$ o en su pura identidad abstracta, exactamente a la misma idea apunta Panikkar. Por ende, las semejanzas de fondo entre ambos pensadores son mucho más notables de lo que a primera vista parece sospecharse. No obstante, esto no impide detectar también ciertas diferencias entre sus planteamientos:

\section{Primera diferencia: Metafisica vs. Teofisica}

Panikkar sigue la misma línea del holismo sustancial de Inciarte en su visión cosmoteándrica, pero extiende la intención de este aún más allá: lo real puede contemplarse desde tres dimensiones distintas: en su misterio, libertad, inconmensurabilidad, como divina; en su espacio-temporalidad, como cósmica; y, en su dimensión noética, en su inteligibilidad y subjetividad, como humana. Es decir, a los ojos de Panikkar la realidad no solo puede entenderse desde las dimensiones de cambio y permanencia, potencialidad y actualidad que Inciarte distingue, pues esta óptica parecería estar limitada a una sola faceta de lo real. Es necesario considerar esto desde una perspectiva más amplia que tome en cuenta una pluridimensionalidad más radical, en un marco que no se limita a la sustancia individual como eje ontológico. De otro modo, se incurre de nuevo en cierto dualismo: se enfrenta lo que está mezclado con potencialidad, a lo divino,

\footnotetext{
${ }^{95}$ Inciarte, F., Imágenes, palabras, signos. Sobre arte y filosofia (IPS), Pamplona: EUNSA, 2004, p. 105.

${ }_{96}$ Ibid., p. 105.

${ }^{97}$ Inciarte, F., Tiempo, sustancia, lenguaje. Ensayos de metafisica, pp. 90-91.

${ }^{98}$ Espinosa, Z., “¿Esencia y nominalismo? Algunas críticas y respuestas en torno a la noción de esencia”, p. 100.
} 
que queda separado de ello al abarcar una sola dimensión, que es la actualidad pura, esencialmente ajena a todo devenir, que es de una vez por todas.

Es preciso observar que, en lugar de hablar de metafisica, Panikkar prefiere hacerlo de teofísica, ya que aquella deja de lado la física. Dice: "La metafísica debe 'escuchar' a la física, pero esta última debe decidir si ha sido correctamente interpretada por aquella". Lo que no debe ocurrir es que se extrapolen las leyes de un ámbito a otro: "Atribuir a la materia leyes semejantes a las que se descubrían en el campo espiritual", o "comprender el mundo espiritual partiendo del material" ${ }^{100}$. Inciarte también rechaza esta extrapolación de las leyes de los fenómenos físicos a los psíquicos, realzando la peculiaridad de estos, su carácter distintivo. Sin embargo, esto no debe hacerse, según Panikkar, a costa de reducir a la nada o de despreciar lo material, pues entonces seguimos atrapados en una visión dualista.

Por ejemplo, de acuerdo con lo que hemos visto, para Inciarte el alma no es ninguna otra cosa más allá del cuerpo, sino que es justamente él mismo pero tomado de distinta manera: "de la forma más alta"101 "en un sentido más comprehensivo y unitario, desde el punto de vista más importante", desde su "'parte' más fuerte o más propia" "102. Esto no significa, según él, adoptar una visión espiritualista que deje de lado uno de los elementos -el cuerpo- al modo platónico, sino que "se puede dejar de lado el cuerpo bajo determinadas circunstancias, a saber, cuando lo que resta incluye el cuerpo y entonces abarca la totalidad del ser vivo" ${ }^{103}$. Sin embargo, según Panikkar podría apreciarse aquí un resto de dualismo y del pensamiento espiritualista que ha permeado la tradición occidental, y que impide reconocer verdaderamente el fondo divino de todo lo real, la sagrada secularidad, la divinidad de lo inmanente. Inciarte seguiría, a juicio de Panikkar, en cierta medida vinculado a este defecto, puesto que Inciarte considera que, para que la forma como acto pueda abarcar en sí todas las demás, se requiere que tenga cierta prioridad o independencia respecto de la materia, esto es, que sea completamente inmaterial. Por esto Panikkar reclama el término de 'teofísica', al considerar que es más comprehensivo o con un potencial expresivo mayor de la pluridimensionalidad de lo real.

\footnotetext{
99 Panikkar, R., La puerta estrecha del conocimiento. Sentidos, razón y fe, p. 151.

${ }^{100}$ Ibid., p. 152.

${ }^{101}$ Inciarte, F., Forma Formarum. Strukturmomente der Thomistischen Seinslehre im Rückgriff auf Aristoteles, Friburgo/Múnich: Karl Alber Verlag, 1970, p. 48.

${ }^{102}$ Inciarte, F., Tiempo, sustancia, lenguaje. Ensayos de metafisica, p. 48.

${ }^{103}$ Inciarte, F., Forma Formarum. Strukturmomente der Thomistischen Seinslehre im Rückgriff auf Aristoteles, p. 32.
} 
Segunda diferencia: La dimensión cósmica o espacio-temporal. El tiempo abstracto vs. el tiempo metafisico

Panikkar quiere subrayar que toda la realidad tiene una dimensión espacio-temporal, pues lo divino, por ejemplo, no es trascendente de modo que fuera puramente ajeno a lo cósmico: es encarnación y, por tanto, Trinidad, relación, y merece la pena enfatizar esta cuestión en la que no se ha reparado suficientemente.

Inciarte está de acuerdo con la importancia del tiempo y lo hace intervenir como un elemento fundamental en su metafisica, pues reconoce que lo único que existe, la sustancia, es temporal no de una manera puramente externa, sino de forma que las cosas siempre están cambiando, incluso cuando no lo parece a primera vista. Toda forma de dar cuenta de lo real que prescinde del tiempo no se sitúa en una posición auténticamente metafísica, y esto se aprecia de forma especial en el caso de la subjetividad humana, cuya peculiaridad se pone de relieve en su trato con el tiempo (retenciones y proyecciones).

Distingue dos tipos de temporalidad. Por un lado, está el tiempo extendido como sucesión de ahoras que es producto de la reconstrucción o representación estática abstracta de la conciencia. Por otro lado, está el tiempo auténticamente real, concreto, el tiempo metafísico que es el ahora instantáneo, no compuesto de partes, indivisible y continuamente cambiante, que está siempre fluyendo (nunc fluens), dejando y empezando a ser. En consecuencia, este último tipo de temporalidad es ex-istente: está fuera de sí, es decir, ex-iste y no consiste ${ }^{104}$, y por ello forma un flujo continuo y no una mera sucesión.

Inciarte considera que la realidad es constitutivamente temporal en este segundo sentido: es algo que nace y perece en el mismo instante ${ }^{105}$, pura tensión entre el ser y la nada, cosa que remite a la idea de una creación continua, que Panikkar también comparte. Este es su carácter genuinamente metafísico, a pesar de que nos cueste reparar en él tanto en la vida cotidiana como en el pensamiento estrictamente científico (físico, histórico, etc.) en la medida en que nuestra imaginación tiende a espacializar, retener -abstrayendo- lo que es esencialmente temporal y, por tanto, inapresable conceptualmente, para formar objetos durables, consistentes o subsistentes y no meramente existentes $\mathrm{y}$, por tanto, divisibles en tantos ahoras, períodos o eventos contiguos como precisemos para nuestros propósitos prácticos. En esto consiste el peculiar

\footnotetext{
${ }^{104} \mathrm{Cf}$. Inciarte, F., Tiempo, sustancia, lenguaje. Ensayos de metafisica, p. 105.

${ }^{105}$ Cf. Ibid., p. 109.
} 
comportamiento "temporizador" de la subjetividad respecto de las cosas, que consiste paradójicamente en su destemporización y posterior espacialización para manejarse en el mundo.

Por tanto, Inciarte ${ }^{106}$ establece una relación intrínseca entre la sustancia como entidad metafisica fundamental y el tiempo en este segundo sentido: la sustancia es cambiante en el mismo sentido en que el único ahora real es fluyente y no estático, pero no cambian ambos en un sentido discontinuo, sustituyéndose unos accidentes o estados, o unos instantes por otros, sino que cambian en tanto que permanecen, de forma continua.

Así pues, si vimos que para Panikkar no se puede obviar la dimensión espacio-temporal o cósmica de ninguna realidad, Inciarte también liga el pensamiento sustancial al tiempo de forma esencial, si bien no tanto al espacio, ya que considera que se malinterpreta la sustancia cuando se la comprende como un núcleo o base espacial, en lugar de hacerlo desde la perspectiva de la función, como acto de lo potencial. Por tanto, la filosofia de Inciarte es una muestra de que el paradigma de la sustancia, lejos de resultar reísta o rigidificador, puede servir para dar cuenta del dinamismo de lo real, que es lo mismo sin ser la misma cosa, como dice Zubiri o, como afirma Inciarte ${ }^{107}$, que permanece a través (y no a pesar) del cambio, es decir, que se modifica en su esencia (se transforma, Veränderung) sin que esto suponga una modificación esencial (cambio, Wechsel).

La importancia del contexto que Panikkar resalta para que las cosas adquieran significatividad es también reconocida por Inciarte. Este no duda de su trascendencia para precisar el significado de las palabras, pero a causa de su pensamiento sustancial defiende que "si las palabras carecieran por sí mismas de toda significación concreta, el contexto tampoco podría dársela, pues no hay ningún contexto lo suficientemente determinado como para lograr esto" ${ }^{108}$. Es decir, debe haber ciertos contenidos significativos distintos, cuya significación pueda determinarse al margen de los juicios en que aparecen. Solo en cierta medida, pero no totalmente, determina el contexto el significado preciso de los conceptos.

Esto es acorde con las diferentes intenciones últimas que ambos autores tienen: la de Panikkar consiste en evolucionar a un modo de conciencia en que

\footnotetext{
${ }^{106}$ Cf. Ibid.

${ }^{107}$ Cf. Ibid.

${ }^{108}$ Espinosa, Z., “¿Sustancias o hechos? La entidad fundamental de una teoría de las categorias”, en: Anuario filosófico, v. XLVII, 2 (2014), p. 437.
} 
no pueda prescindirse de la relación-que se da siempre en un contexto concreto $\mathrm{y}$, por tanto, desde cierto devenir- para comprender la estructura auténtica de los seres, mientras que Inciarte -que también relaciona sustancia y tiempo de manera intrínseca-, más que centrarse en un tiempo extendido -que en realidad no existe propiamente, sino que es pura reconstrucción (lógica) de la conciencia- quiere destacar la oposición metafísica fundamental entre ser y nada que se percibe en la existencia temporal de la sustancia, cuando esta se entiende en sentido estrictamente metafísico: como lo único real.

Si Panikkar contrasta la ex-istencia y la in-sistencia, en el caso de Inciarte el contraste se da más bien no solo entre ex-istencia y con-sistencia o subsistencia (duración a lo largo de un tiempo extendido), sino fundamentalmente entre el ser como existencia o como hecho unívoco y el ser como actualidad. El in-sistir espacio-temporal es importante para él en el caso del ser finito, pero más importante es comprender la diferencia entre el ser como hecho y el ser como acto, que corresponde a la que se da entre un existir unívoco y el ser análogo. Aquel puede afirmarse de todo lo que cae bajo el alcance del cuantificador, y así se comprende el ser como género extensivo. Sin embargo, este se da en sentido intensivo, como la actualidad que constituye lo más propio de cada ser. Llano ${ }^{109}$ afirma que esta distinción resulta evidente en casos como el del mal o el Ser Absoluto: aquel existe, pero no es (en ningún sentido positivo, pues no es nada de suyo) y, respecto al Ser Absoluto, si bien de este también puede decirse que existe, lo más característico de él es su actualidad.

Tercera diferencia: Un intento de superación de la analogía: la equivalencia homeomórfica.

Los conceptos de analogía y equivalencia homeomórfica adquieren una importancia de primer orden en las propuestas de ambos autores: para Inciarte los conceptos análogos, frente a los unívocos, dan cuenta de lo real de la manera más ajustada posible (pues se refieren a la realidad concreta, a la individualidad diferencial, y no meramente a una identidad lógica abstracta), si bien son menos claros que los unívocos o más dificiles de captar para la mente humana, ya que esta no puede hacerse directamente con la individualidad. Estos últimos, los conceptos unívocos, para nosotros deben su claridad a que se derivan de una comprensión puramente mental o lógica de lo real y, en consecuencia, separadora de las formas a las que se concibe como identidades abstractas

${ }^{109}$ Cf. Llano, A., Metafisica y lenguaje, Pamplona: EUNSA, 1984. 
invariables a través de sus distintas ejemplificaciones. Para Panikkar, por su parte, la equivalencia homeomórfica constituye el primer paso en la apertura a la comprensión de lo(s) otro(s). En concreto, establece un puente o enlace entre propuestas culturales o tradiciones distintas e inconmensurables.

En primera instancia, ambos conceptos se plantean como intento de mediación entre lo que es esencialmente diverso, aunque no incompatible o irreconciliable. En el caso de Inciarte, en efecto, la analogía indica que no hay total equivocidad, y en el de Panikkar todo lo real comparte la misma estructura triádica. Sin embargo, la noción de equivalencia homeomórfica como propuesta innovadora de Panikkar intenta recoger de forma más explícita la esencial heterogeneidad entre los mundos culturales que se dan, irreductibles a una base común o sustrato compartido. En este sentido, Panikkar la sitúa como analogía de tercer grado, más allá de la mera analogía convencional, y denuncia que en esta todavía se mantiene la primacía o prioridad del primer analogado, conforme al cual se comparan los demás.

Esto es, Panikkar interpretaría que la analogía -ya sea según la intención, según el ser, o según la intención y según el ser-supone todavia la instalación en un cierto tipo de dualismo y, en consecuencia, sigue adoleciendo de los defectos del pensamiento exclusivamente conceptual, por mucho que los conceptos se conciban aquí como análogos y no solo como unívocos. Así pues, por ejemplo, la analogía según el ser está más cerca de ese dualismo denunciable que la analogía según la intención, pero ninguna escapa del marco limitado de este, que va ligado a la prioridad del pensamiento conceptual. Por ello, la propuesta del holismo cosmoteándrico de Panikkar busca acabar con este remanente de dualismo que se percibe en el pensamiento basado en la analogía, el cual aún prioriza uno de los extremos (el analogado principal) y sigue siendo, por ello, separador y disgregador, para reparar en la relacionalidad fundamental de lo real.

Otra diferencia entre la analogía y la equivalencia homeomórfica es que para Panikkar "no es posible establecer antes del encuentro con el otro justo qué términos representarian estas zonas de acuerdo" ${ }^{110}$, mientras que en Inciarte puede hablarse de analogía antes de cualquier encuentro con ello. Precisamente la analogía es la herramienta (conceptual) que emplea Inciarte para, desde el propio logos, abordar lo Absoluto sin estar en ello. Por definición, el pensamiento -y no menos el pensamiento análogo- procede objetivando aquello que

${ }^{110}$ Gómez, C. M., "La hermenéutica intercultural de Raimon Panikkar", p. 30. 
tiene ante sí, es objetivizador, es decir, pone distancia entre su sujeto y la cosa conocida. Sin embargo, según Panikkar las equivalencias homeomórficas no pueden determinarse de modo previo al acercamiento al otro, de manera que su identificación pone en juego algo más que la pura comprensión racional, en la medida en que brotan de un verdadero encuentro como conversión existencial o vivencial al otro. El pensamiento análogo no presenta esta exigencia, en tanto que sigue teniendo lugar en el puro plano conceptual. Representa precisamente la capacidad de la facultad racional de hablar de lo otro que sí la presenta, desde sí misma. Por tanto, la mediación que establece Inciarte a través de la analogía es una mediación puramente gnoseológico-objetivizadora, mientras que la de la equivalencia homeomórfica de Panikkar rebasa este plano.

Cuarta diferencia: El holismo cosmoteándrico, ¿holismo total? El problema de la unidad

Por otra parte, como establecimos más arriba, Panikkar sostiene que, al considerar el todo orgánico de lo real, las relaciones han de ser tan fuertes como los elementos que se ponen en relación. En cambio, desde el holismo sustancial de Inciarte no hay relación que valga, no hay siquiera necesidad de relaciones como algo añadido porque estas no son necesarias cuando se ha superado un pensamiento categorial, al estar contenidas en la propia forma entendida como actualidad. Entonces, la unidad entre las distintas dimensiones de las cosas es originaria, por lo que la pregunta por su unión no tiene lugar, llega siempre tarde, está mal enfocada o parte de una metafísica deficiente. Esto se debe a que no se trata de ningún compuesto ni se trata de unir - a posteriori-algo que fuera previamente independiente.

Si bien esto puede mantenerse en referencia a la sustancia como entidad metafisica primaria, como hace Inciarte, cuando lo extrapolamos a todo lo real, pasando así de un holismo sustancial a uno cosmoteándrico, aparece la duda de si realmente pueden mantenerse ciertas distinciones entre lo que existe al haber perdido el eje ontológico de la sustancia. En efecto, lo que separa a ambos 344 pensadores son los distintos enfoques que adopta cada uno: el de Inciarte es micro (basado en la sustancia individual como referencia fundamental del pensamiento), mientras que Panikkar adopta una perspectiva macro, al contemplar todo lo real como una totalidad orgánica. Si el horizonte metafísico de Inciarte se extiende hasta dar con las nociones de potencialidad y actualidad como dimensiones últimas de lo real, para Panikkar estas corresponden a lo cósmico, lo humano y lo divino. 
Si bien resulta claro que el holismo sustancial de Inciarte no puede asimilarse en absoluto a un holismo total como el de Anaxágoras -en la medida en que hay auténticas distinciones entre los seres proporcionadas por el principio ontológico de la sustancia- esto no está tan claro en el caso de Panikkar. Este se refiere efectivamente a una distinción de los elementos que conforman la naturaleza triádica de lo real, pero ciertamente su holismo es más profundo que el de Inciarte, en la medida en que descarta la sustancia como unidad de referencia metafísica. Por ello, parece que al prescindir de esta, o bien sacrifica la distinción entre las cosas y entonces efectivamente da cuenta de su unidad, pero esta se convierte, en contra de lo que dice, en una unidad indiscriminada, en un monismo; o bien mantiene cierta diversidad entre las dimensiones de lo real. No obstante, en este último caso, si estas siguen concibiéndose como contenidos, como Panikkar parece hacer (cósmico, divino, humano), no puede darse cuenta de su relación de forma adecuada, pues esta exigiría, como hemos visto, la añadidura o la intervención de una relación como elemento adicional, y así no se logra en último término fundamentar una unidad auténticamente originaria.

Esta constituye la crítica que afectaría de la manera más interna al planteamiento metafísico de Panikkar. Para Inciarte, la sustancia es absolutamente imprescindible para no caer en una posición holista. Para él la función y, por tanto, la relacionalidad, es dependiente de algo que es, por lo que esto debe admitirse como reconocimiento de que hay entidades distintas en la realidad y no todo es lo mismo. Esto no significa que su determinación deba ser absoluta o universal, puesto que presenta cierta relatividad o flexibilidad en atención a nuestros intereses culturales, pero esta no puede ser completa. De hecho, como sostiene Tomás de Aquino ${ }^{111}$, la necesidad de considerar la función es esencial a la hora de determinar las cosas como una (si se las considera en cierto orden) o como muchas (de forma independiente y en sí mismas, como un compuesto). Pero deben poder delimitarse ciertas unidades de sentido como sujeto de las proposiciones. De otro modo, estas quedarían disueltas y no se sabría de qué se está hablando.

Sin embargo, para Panikkar la propuesta de Inciarte caería probablemente bajo el lado de un modelo pluralista atomista, en tanto que, aunque se mantiene la unidad originaria de los elementos que integran cada sustancia individual, no ocurre asi respecto a las distintas sustancias que se dan en el mundo. Esto es así porque su planteamiento no deja clara su relación, tanto

\footnotetext{
${ }^{111}$ Cf. Aquino, T., De veritate, q.22: el apetito del bien. Introducción, traducción y notas de Juan Fernando Sellés, Pamplona: EUNSA, 2001.
} 
aquella que se pueda dar entre las sustancias finitas entre sí, como la que se da entre estas y la sustancia divina como pura actualidad. En otras palabras, si bien Inciarte logra dar cuenta de la relatividad radical o interdependencia de las dimensiones diferentes de cada sustancia individual, no logra lo mismo respecto al conjunto de sustancias diferentes. Por eso, Panikkar consideraría que hay que extender la comprensión que tiene Inciarte respecto de la relación materia-forma a todo lo demás.

Inciarte admitiria, en efecto, que el reconocimiento de la sustancia supone introducir pluralismo en el mundo, pero este no es necesariamente un atomismo, esto es, no significa ausencia de relación. De hecho, da con un principio que supone el eje vertebrador -la relación- de todo lo real: la actualidad. Todos los entes pueden comprenderse como acto, que sirve como principio compartido o unificador de todo lo que es, y que se combina en diversa medida con la potencialidad en cada caso. Es decir, ofrece un principio de comprensión de toda la realidad que actuaría a modo de unidad de todo ello: todo -lo cósmico, lo humano y lo divino, en el paradigma de Panikkar- puede interpretarse bajo las herramientas que Inciarte proporciona, en tanto que estas no se limitan a contenidos determinados, sino que miran a la modalidad que se repite estructuralmente (análogamente) en cada tipo de cosa. La actualidad constituye la dimensión divina, pero también la cósmica -es actividad, no pasividad o quietud-, y también la humana, como su realización. Puede manifestarse en el devenir espacio-temporal en su relación con la potencia, o en el presente instantáneo, en el ahora metafísico, que es el único estrictamente real.

Por tanto, para Inciarte lo que propiamente es es, en último término, el ser como actualidad, que "abarca la totalidad de lo que hay, atraviesa todas las formalidades... porque todo lo que hay participa necesariamente de él en distintos grados"112. Además, en la medida en que el acto abarca en sí todas las demás formalidades -pues es acto de (algo potencial), es decir, es intrínsecamente relacional-, se logra una verdadera integración no solo de todas las distintas sustancias, que lo comparten en tanto que son reales, sino también de los diversos elementos que integran la sustancia (de todas sus otras formas y su materia), que quedan conservadas en él bajo la forma de la potencialidad.

Parece que Panikkar no logra dar cuenta de la unidad o de la relacionalidad de lo real de la manera tan lograda como lo hace Inciarte, pues su concepción triádica sigue ligada en cierta medida a los contenidos (divino,

\footnotetext{
${ }^{112}$ Espinosa, Z., “¿Esencia y nominalismo? Algunas críticas y respuestas en torno a la noción de esencia”, p. 103.
} 
cósmico y humano). En cambio, la actualidad (que no niega, sino que es susceptible de combinarse con la potencialidad) puede aplicarse a todo lo real en la medida en que no es ningún contenido. Así, constituye, respecto al conjunto de lo real, lo compartido entre las distintas cosas y, respecto a cada ser, el mayor principio unificador: la unidad de una diversidad de elementos que quedan conservados en ella -conservados bajo el modo de la potencialidad-a la manera de una forma formarum.

\section{Conclusión}

Por tanto, hay que notar que, para Inciarte, mantener la primacía ontológica de la sustancia no significa renunciar al pensamiento funcional, estructuralo relacional que propone Panikkar. Inciarte cree que ambas cosas son compatibles, y que puede mantenerse el paradigma de la sustancia, pero hay que interpretarla correctamente. El pensamiento basado en ella no es necesariamente un pensamiento reísta ${ }^{113}$, espacialista o dualista si se comprende bien, a saber: precisamente cuando se observa desde el punto de vista funcional o modal: como actualidad y no como mero contenido. Si Panikkar enfatiza la función, frente a la sustancia, Inciarte expone cómo precisamente esta puede abarcar aquella, por lo que no deben entenderse como contrapuestas, y lo que ocurre ante la crítica de Panikkar a la idea de sustancia es que este ha caído presa de la interpretación errónea de ella tan extendida.

No cabe duda de que Inciarte defiende, como Panikkar, la necesidad de un pensamiento de sistema, pues se refiere explicitamente a la sustancia individual como una forma formarum o sistema de sistemas. Esto se posibilita al adoptar el punto de vista modal-relacional, ya que entonces no se comprenden los elementos constitutivos de la sustancia como qués que se suman o se van añadiendo, sino que el último de ellos (que es también el primero, en tanto que la sustancia aparece -de golpe- cuando este se da) abarca a todos los demás como su realidad o actualidad, sirviendo de factor máximamente cohesivo: "No se puede partir de determinaciones eidéticas separadas para hacerlas llegar a un sujeto subyacente como impronta inevitable del logos predicativo; más bien hay que empezar por la cosa existente individual como un sistema de determinaciones y ver en estas determinaciones suyas aquello en lo que consiste la cosa, en virtud de la mutua referencia sistemática de estas" ${ }^{114}$.

\footnotetext{
${ }^{113}$ Con esto me refiero a algo estático o sustancialista.

${ }^{114}$ Inciarte, F., Forma Formarum. Strukturmomente der Thomistischen Seinslehre im Rückgriff auf Aristoteles, p. 161.
} 
Podría parecer que fuera Panikkar quien hubiera escrito esto. Aquí Inciarte concibe nitidamente la realidad (para él, sustancia) como sistema en que todos los elementos están interpenetrados, son meras dimensiones o aspectos de lo real, de forma que no pueden existir por separado. Por tanto, puede notarse cómo el pensamiento de la sustancia no está tan lejos del pensamiento de sistema como muchas veces se ha pensado. De este modo, hay una coincidencia de fondo, una unidad de intención entre ambos planteamientos, que se establece, a pesar de todo, por distintos caminos y con diversas herramientas conceptuales.

Recibido: 28/03/2019

Aceptado: 24/03/2020

\section{Bibliografia:}

Strayer, J. y H. Gatzske, El desarrollo de la civilización, Nueva York: Hardcourt Brace and World, 1961.

Menéndez, R., "La propuesta utilitarista", en: Granados, E. (ed.), Debates éticos contemporáneos, México D.F.: Siglo XXI, 1998, pp. 234-267.

Nussbaum, M., "La ética de la virtud: una categoría equívoca", en: Areté, v. XI, 2 (1999), pp. 573-613.

Allaire, E. B., "Existence, Independence and Universals", en: Allaire, E. B. (ed.), Essays in Ontology, La Haya: Martinus Nijhof, 1963, pp. 1-13.

Aquino, T., De veritate, q.22: el apetito del bien. Introducción, traducción y notas de Juan Fernando Sellés, Pamplona: EUNSA, 2001.

Aristóteles, Metafisica, Madrid: Gredos, 1994.

Aristóteles, Acerca del alma, Madrid: Gredos, 1999.

Cirlot, V., Melloni, J., Tamayo, J. J. y Saranyana, J. I., “2018, el año Panikkar”, en: El Ciervo: revista mensual de pensamiento y cultura, 769 (2018), pp. 16-19.

Espinosa, Z., "La identidad del sujeto individual a través del modelo de la sustancia: un contraste entre F. Inciarte y R. Grossmann", en: Pensamiento y cultura. Revista de Filosofia, v. XVI, 1 (2013), pp. 41-66. https://doi.org/10.5294/pecu.2013.16.1.2

Espinosa, Z., “¿'Sustancias o hechos? La entidad fundamental de una teoría de las categorias”, en: Anuario filosófico, v. XLVII, 2 (2014), pp. 413-450.

Espinosa, Z., Percepción, pensamiento y lenguaje. El realismo radical de Reinhardt Grossmann y el realismo moderado de Fernando Inciarte, Pamplona: EUNSA, 2015.

Espinosa, Z., “¿Esencia y nominalismo? Algunas críticas y respuestas en torno a la noción de esencia”, en: Acta Philosophica, v. XXIV, 1 (2016), pp. 87-110.

Gómez, C. M., "La hermenéutica intercultural de Raimon Panikkar", en: Franciscanum, LVII, 164 (2015), pp. 19-43. https://doi.org/10.21500/01201468.1541 
Grossmann, R., The Categorial Structure of the World, Bloomington: Indiana University Press, 1983.

Inciarte, F., Forma Formarum. Strukturmomente der Thomistischen Seinslehre im Rückgriff auf Aristoteles, Friburgo/Múnich: Karl Alber Verlag, 1970.

Inciarte, F., "Anhang", en: Hüntelmann, R. y Tegtmeier, E. (eds.), Neue Ontologie und Metaphysik, San Agustón: Academia, 2000, pp. 167-196.

Inciarte, F., Tiempo, sustancia, lenguaje. Ensayos de metafisica, Pamplona: EUNSA, 2004. Inciarte, F., Imágenes, palabras, signos. Sobre arte y filosofia, Pamplona: EUNSA, 2004.

Inciarte, F., First Principles, Substance and Action. Studies in Aristotle and Aristotelianism, Hildesheim/Zürich/Nueva York: Olms, 2005.

Inciarte, F., Cultura y verdad, Pamplona: EUNSA, 2016.

Llano, A., Metafisica y lenguaje, Pamplona: EUNSA, 1984.

Manimala, V. J., "Raimon Panikkar, The Rhythm of Being: The Gifford Lectures. A Review Article”, en: Exchange, 40 (2011), pp. 192-200. https://doi. org/ 10.1163/157254311X562053

Orrego, C., "Fe y razón en la filosofia católica: la propuesta de Alasdair MacIntyre", en: Veritas, 33 (2015), pp. 9-23. https://doi.org/10.4067/S0718-92732015000200001

Panikkar, R., "La visión cosmoteándrica: el sentido religioso y emergente del tercer milenio”, en: Qüestions de Vida Cristiana, 156 (1991), pp. 78-102. Recuperado de: http://www.seleccionesdeteologia.net/selecciones/llib/vol32/125/125_panikkar. pdf

Panikkar, R., La nueva inocencia, Estella: Verbo Divino, 1993.

Panikkar, R., The Intrareligious Dialogue, Nueva York: Paulist Press, 1999.

Panikkar, R., Paz e interculturalidad. Una reflexión filosófica, Barcelona: Herder, 2006.

Panikkar, R., La puerta estrecha del conocimiento. Sentidos, razón y fe, Barcelona: Herder, 2009.

Panikkar, R., The Rhythm of Being. The Gifford Lectures, Nueva York: Orbis Books, 2010.

Velázquez Fernández, H., “¿Es la naturaleza humana modificable mediante la biotecnologia? Transhumanismo: del perfeccionamiento ético al enhancement", en: Naturaleza y Libertad, 10 (2018), pp. 347-372. https://doi.org/10.24310/nyl. v10i3.3677

Vilanova, E., "Prólogo", en: Panikkar, R., La nueva inocencia, Estella: Verbo Divino, 1993, pp. 9-24. 